\author{
Timothy Hardy, Quentin M. Anstee, and Christopher P. Day
}

\begin{abstract}
Purpose of review
Nonalcoholic fatty liver disease is the most common cause of liver dysfunction in the western world because of its close association with obesity, insulin resistance and dyslipidaemia. Nonalcoholic steatohepatitis (NASH) is a particular health concern due to the increased morbidity and mortality associated with progressive disease. At present, without specific targeted pharmacological therapies, the mainstay of therapy remains weight loss through dietary modification and lifestyle change; thus, the purpose of this review is to summarize the recent evidence for current and emerging therapies in NASH.
\end{abstract}

\title{
Recent findings
}

Some existing medications, including pioglitazones and angiotensin receptor antagonists, may be repurposed to help treat this condition. Vitamin E may improve histology in NASH, but safety issues limit its use. Recently, a number of novel agents specifically targeting nonalcoholic fatty liver disease pathogenesis have entered clinical trials, including the farnesoid $X$ receptor agonist obeticholic acid, which has shown significant histological improvements in steatohepatitis and fibrosis.

\begin{abstract}
Summary
Diet/lifestyle modification remains the mainstay of treatment. For patients with NASH and advanced fibrosis, current liver-directed pharmacotherapy with vitamin $\mathrm{E}$ and pioglitazone offer some benefits; obeticholic acid appears promising and is currently being tested. Comorbidities must be diagnosed and treated; cardiovascular disease remains a primary cause of death in these patients.
\end{abstract}

\section{Keywords}

nonalcoholic fatty liver disease, nonalcoholic steatohepatitis, treatment

\section{INTRODUCTION}

Nonalcoholic fatty liver disease (NAFLD) is the most common cause of liver dysfunction in the western world [1] because of its close association with obesity, insulin resistance and dyslipidaemia; it is therefore considered the hepatic manifestation of the metabolic syndrome. A particular health concern is patients with nonalcoholic steatohepatitis (NASH) with accompanying hepatocellular injury that can lead to progressive liver fibrosis, cirrhosis and hepatocellular carcinoma (HCC) as well as increased cardiovascular risk [1]. At present, there is no approved therapy for NASH and the optimal treatment remains uncertain; effective therapies are thus a research priority to reduce the anticipated burden of liver disease.

\section{THERAPY}

The rationale for therapeutic approaches is centred on the concept that while simple steatosis has not been associated with morbidity, NASH is associated with a more than 10-fold increased risk of liverrelated death (2.8 vs. $0.2 \%)$ and a doubling of cardiovascular risk [2]; at the time of diagnosis, $25-33 \%$ of patients with NASH have advanced fibrosis, including cirrhosis [3,4]. After adjustment for confounders, NASH has a similar fibrotic potential to that of chronic hepatitis $\mathrm{C}[3,4]$. Pooled data suggest that about $21 \%$ of patients with NASH will have some regression of fibrosis while $38 \%$ of patients will progress over 5.3 years' follow-up [3], results that have recently been confirmed in a dualbiopsy Northern European population [5"'].

Liver Research Group, Institute of Cellular Medicine, The Medical School, Newcastle University, Newcastle-Upon-Tyne, UK

Correspondence to Professor Christopher P. Day, Pro-Vice Chancellor and Provost of Medical Sciences, Medical Sciences Faculty Office, The Medical School, Newcastle University, Framlington Place, NewcastleUpon-Tyne, NE2 4HH, UK. Tel: +44191222 7003; fax: +44191222 6621; e-mail: c.p.day@ncl.ac.uk

Curr Opin Gastroenterol 2015, 31:175-183

\section{DOI:10.1097/MOG.0000000000000175}

This is an open-access article distributed under the terms of the Creative Commons Attribution-NonCommercial-NoDerivatives 4.0 License, where it is permissible to download and share the work provided it is properly cited. The work cannot be changed in any way or used commercially. 


\section{KEY POINTS}

- Diet and lifestyle modification, with weight loss, remain the mainstay of treatment for NAFLD.

- Vitamin E and pioglitazone offer some benefit in selected cases (NASH and bridging fibrosis), although these must be balanced with potential adverse effects.

- Obeticholic acid may provide the first liver-targeted therapy for NASH.

- Cardiovascular disease must be diagnosed and treated.

\section{Lifestyle modifications}

Weight reduction is recommended as the initial step in management of NASH. Pharmacological agents such as orlistat may help achieve weight loss; however, whether these confer additional independent benefit beyond that due to weight loss is unclear $[6,7]$. Lifestyle modification therefore remains the primary therapy for weight reduction, particularly in the absence of approved pharmacotherapy; it encompasses diet, physical activity (aerobic and resistance) and behavioural change, or a combination of all three. Trial evidence shows that weight reduction more than $7 \%$ sustained over 48 weeks is associated with significant reduction in histological severity of NASH [8]. A systematic review of the available evidence for lifestyle modifications in NAFLD has recently been conducted [9]. Less than $50 \%$ of patients achieve the necessary weight loss goal of more than $7 \%$ in the trial setting [8], and many have questioned the sustainability of this type of intervention [10]. Resistance training, which is less burdensome on the cardiovascular system, shares the metabolic improvements seen in more strenuous aerobic exercise and may be more sustainable [11]. Nevertheless, in the many patients that fail to implement lifestyle changes or have advanced disease (bridging fibrosis) on index biopsy, specific liver-directed pharmacotherapy may be needed. No drugs are currently licensed specifically for treating $\mathrm{NASH}$; there is an urgent need for well designed randomized controlled trials (RCTs) with appropriate endpoints to narrow this gap. Table 1 [12-21, 22"-,23-25] summarizes the current evidence for therapies in NASH.

\section{Therapies of potential value for the treatment of nonalcoholic steatohepatitis}

Very few large RCTs have been published on which evidence-based treatment for NASH is recommended. Therapies with potential benefit in NASH include thiazolidinediones (TZDs) and vitamin E.

\section{Thiazolidinediones}

The most extensively studied and for which the best data are available is for the use of TZDs in the treatment of NASH [4]. Central to their action is their ability to ameliorate insulin resistance and promote fatty acid uptake peripherally [26]; free fatty acids are thus diverted away from the liver towards adipose tissue.

TZDs activate the master adipocyte differentiation regulator, peroxisome proliferator-activated receptor (PPAR) $\gamma$, allowing transdifferentiation of preadipocytes into insulin-sensitive, fat-storing adipocytes [27-29]. Interestingly, PPAR $\gamma$ ligands also attenuate liver fibrosis by suppressing the transdifferentiation of hepatic stellate cells into activated

Table 1. Summary of agents tested in nonalcoholic steatohepatitis

\begin{tabular}{|c|c|c|}
\hline Benefit & Agent & Comment \\
\hline \multirow[t]{2}{*}{ Potential benefit } & Pioglitazone & Improves components of the NAS score [12]. Increased risk of bladder cancer and MI $[13,14]$. \\
\hline & Vitamin $\mathrm{E}$ & Significant improvement in histological lesions [12]. However, may increase all-cause mortality [15]. \\
\hline \multirow[t]{6}{*}{ No clear benefit } & Metformin & No effect on histology $[16,17]$. \\
\hline & Statins & \\
\hline & Atorvastatin & No histological data, but improves liver enzymes and radiological steatosis $[18,19]$. \\
\hline & Simvastatin & No effect on histology or liver enzymes [20]. \\
\hline & UDCA & Histological data lacking, four RCTs showed no effect on liver enzymes [21]. \\
\hline & PUFAs & No histological improvement in activity [22"-], but reduction in steatosis radiologically [23]. \\
\hline \multirow[t]{2}{*}{ Unclear benefit } & $\begin{array}{l}\text { Angiotensin } \\
\text { receptor } \\
\text { blockers }\end{array}$ & Improvements in histology (necroinflammation and fibrosis) but study limited to seven patients [24]. \\
\hline & Pentoxyfylline & Improvement in NASH activity score, but not in fibrosis stage. Study limited to 55 patients [25]. \\
\hline
\end{tabular}

MI, myocardial infarction; NAFLD, nonalcoholic fatty liver disease; NAS, NAFLD activity score; NASH, nonalcoholic steatohepatitis; PUFAs, polyunsaturated fatty acids; RCT, randomized controlled trial; UDCA, ursodeoxycholic acid. 
myofibroblasts suggesting an additional direct hepatoprotective effect [30-32]. They also have antiinflammatory effects [33] and increase circulating adiponectin, an antisteatogenic and insulin-sensitizing adipokine [34,35].

The largest multicentre RCT to date included 247 nondiabetic noncirrhotic patients with biopsyproven NASH who received pioglitazone $(30 \mathrm{mg} /$ day), vitamin E (800 IU/day) or placebo for 96 weeks. Histological improvement that included a reduction of two points in the NAFLD activity score (NAS) with no worsening of fibrosis was the primary endpoint; pioglitazone failed to achieve a statistically significant effect compared with placebo [12]. However, it did significantly improve each individual component of the NAS score (steatosis, lobular inflammation and ballooning). When the analysis was confined to patients with definite steatohepatitis on their index biopsy, pioglitazone achieved the primary endpoint. Several other well conducted trials have shown improvements in steatosis, necroinflammation and ballooning [36-38]; however, to date, no study has shown a definite improvement in fibrosis, which is not surprising given the relatively short follow-up periods in most studies. TZD-mediated effects seem to be abrogated upon treatment discontinuation; at 3 months, alanine transaminase (ALT) and homeostatic model assessment return to baseline. In seven out of nine patients who discontinued medication, recurrent NASH was seen at a 48-week posttherapy biopsy [39].

Unfortunately, side-effects (weight gain [40], bone loss/fracture risk [41], increased risk of myocardial infarction with rosiglitazone [13], increased risk of bladder cancer with pioglitazone [14]) and the possible need for long-term therapy [39] have limited widespread acceptance, with rosiglitazone withdrawn from the market in most countries. Pioglitazone remains available and current guidelines suggest consideration in older patients with biopsyproven advanced fibrosis that are unable to adopt or maintain lifestyle intervention, with continued metabolic risk factors; caution is required in patients with diabetes or those with heart failure $[4,42]$.

\section{Vitamin E}

Apart from targeting aspects of the metabolic syndrome that may have beneficial liver effects, liverspecific therapies have also been investigated in NASH. The role of oxidative stress in disease pathogenesis, in particular, has initiated several studies of antioxidants, primarily vitamin E. Vitamin E consists of eight tocopherols; $\alpha$-tocopherol is the most active. Its presence in the phospholipid bilayer of cell membranes allows prevention of the nonenzymatic oxidation of cell constituents by free radicals.
Vitamin E may also inhibit profibrotic activity $[43,44]$ and downregulates nuclear factor (NF)-кBmediated inflammatory pathways in the liver [45]. Preclinical in-vitro and in-vivo studies have shown that in two fibrosis models, vitamin E can ameliorate liver injury blocking both apoptotic pathways and mitochondrial toxicity $[46,47]$.

The Pioglitazone versus Vitamin E versus Placebo for the Treatment of Nondiabetic Patients with Nonalcoholic Steatohepatitis (PIVENS) trial, described earlier, is the largest and most recent study comparing pioglitazone and vitamin $\mathrm{E}$ at $800 \mathrm{IU} / \mathrm{day}$ to placebo in nondiabetic, noncirrhotic patients; it reported that vitamin E improved all histological lesions in NAFLD except for fibrosis, and patients taking vitamin $\mathrm{E}$ had a greater than two-point improvement on NAS score significantly more often compared with placebo [12]. A pilot study suggested that pioglitazone and vitamin $\mathrm{E}$ are superior to pioglitazone alone but the study was not appropriately powered [48]. The positive and encouraging results seen in adult NAFLD may not extrapolate to paediatric NAFLD. The largest trial of vitamin $\mathrm{E}$ in paediatric NAFLD, the Treatment of NAFLD in Children (TONIC) trial, randomly assigned children and adolescents to receive vitamin E (800 IU/day) vs. metformin ( $1 \mathrm{~g} /$ day) or placebo for 2 years. Vitamin E significantly improved hepatocyte ballooning but not lobular inflammation, steatosis nor fibrosis. The primary endpoint of reduction in ALT levels, more often than placebo, was not met [16].

The results of these studies with vitamin E need to be balanced against the emerging body of data that vitamin E may increase all-cause mortality: an additional 39 deaths per 10000 people for those on high-dose (400 IU/day) vitamin $\mathrm{E}$ in a dose-dependent manner starting at $150 \mathrm{IU} /$ day, much less than the doses trialled in NASH [15]. Furthermore, vitamin E therapy may be associated with an increase in prostate cancer in men above 50 years old according to a large study of 35000 patients, and a 20\% increased risk of haemorrhagic stroke $[49,50]$. In light of these risks, the current American Association for the Study of Liver Diseases guidelines recommend that use of vitamin E may be considered in nondiabetic adults with NASH, but not diabetic patients or children [28].

\section{Therapies with no clear benefit}

Several well recognized pharmacotherapies have been investigated in NASH; currently, they are not recommended for its treatment.

\section{Metformin}

Although metformin initially seemed promising in animal models of NASH [51], no histological 
improvement in steatohepatitis has been shown in RCTs in adult and paediatric NASH $[16,17]$. Lowdose metformin could not mitigate the weight gain associated with rosiglitazone in a recent RCT [52], although its effect seems likely to be through weight loss in the small number of treated patients [53]. As it has no effect on histology, metformin is not currently recommended as a targeted treatment for NAFLD.

\section{Statins}

Statins are well recognized in the treatment of dyslipidaemia, but their use as a specific treatment for NAFLD is not well evidenced. Data from the Greek Atorvastatin and Coronary Heart Disease Evaluation study did, however, demonstrate a fall in ALT levels with atorvastatin [19] and the St Francis Heart Study showed a reduction in steatosis radiologically with $20 \mathrm{mg}$ daily of atorvastatin combined with vitamins $\mathrm{C}$ and $\mathrm{E}$ [18]. There are, however, no histological data currently available to support the use of atorvastatin for NAFLD. Although histological data exist for simvastatin, in a trial of 10 patients with biopsyproven NASH, there was no statistically significant improvement in serum liver enzymes, hepatic steatosis, necroinflammatory activity or stage of fibrosis within or between treatment and placebo [20]. However, its use to reduce cardiovascular risk in patients with NAFLD is clear and there is no evidence to suggest that patients with NAFLD are at increased risk of statin-related liver injury [54].

\section{Ursodeoxycholic acid}

Ursodeoxycholic acid (UDCA), by preventing apoptosis and downregulating inflammatory pathways, is an example of a potential cytoprotective agent investigated in NASH. The largest study to date comparing UDCA and placebo showed an unanticipated improvement in the placebo arm, making the effect of the drug hard to interpret [55]. A Cochrane review of four randomized trials using UDCA showed no significant improvement in liver function tests and histological data were lacking [21]. Until there is evidence of clear histological benefit, UDCA cannot be currently recommended for NASH.

\section{Polyunsaturated fatty acids}

Despite preliminary data from small studies suggesting that $\omega-3$ polyunsaturated fatty acid supplementation reduces liver fat content [23], a large trial testing two doses of ethyl-eicosapentaenoic acid did not show any histological efficacy [22"'].

\section{Therapies with unclear benefit}

Some agents tested in NASH have robust preclinical data, but are yet to be investigated in large RCTs.

\section{Angiotensin receptor blockers}

Angiotensin receptor blockers are well established in the treatment of hypertension, a second key component of the metabolic syndrome. Experimental work has clearly shown that angiotensin II promotes survival of hepatic myofibroblasts by activation of ІкB kinase-mediated phosphorylation of NF-кB subunit RelA [56]. A small pilot study of seven patients with NASH treated with losartan for 48 weeks showed improvements in necroinflammation and fibrosis [24]. Larger studies examining the utility of this agent are ongoing.

\section{Pentoxifylline}

Pentoxifylline (PTX) is a tumour necrosis factor- $\alpha$ agonist and reduces production of oxygen-free radicals [57]. Animal models have also suggested an antifibrotic effect together with significantly reducing steatohepatitis [58]. The largest and most recent RCT published in 2011 included 55 patients with NASH receiving PTX or placebo; patients on PTX showed a mean 1.6-point improvement on the NAS score vs. 0.1 point in placebo. Although not significant, there was a slight improvement in fibrosis [25]. Before PTX can be recommended as primary therapy, larger and more compelling data are warranted.

\section{Novel approaches}

New therapies with strong experimental evidence are currently being trialled in human NASH, and may provide hope of a targeted pharmacotherapy; these are summarized in Table 2 [59-66].

\section{Caspase inhibition (GS-9450)}

Preclinical models have shown that hepatocyte apoptosis is a hallmark of NASH [67], the extent of which correlates with disease severity. In a recent phase-2 placebo-controlled trial, 124 patients with histologically characterized NASH were randomized to once-daily placebo or GS-9450, a selective caspase inhibitor, at varying dosages for 4 weeks. In the highest dose group ( $40 \mathrm{mg}$ ), both ALT and cytokeratin-18 fragment levels improved but only ALT reached significance; GS-9450 was safe and well tolerated [68].

\section{PPAR agonists (GFT-505)}

GFT-505 is a dual PPAR $\alpha$ and PPAR $\delta$ agonist that in animal models of dietary-induced NASH has shown a reduction in steatosis, inflammation and proinflammatory genes; interestingly, GFT-505 has also demonstrated antifibrotic properties, independent of metabolic abnormalities [69"]. Human studies have shown that GFT-505 improves liver function 
Table 2. Novel agents currently being tested in, or completed, phase 2 trials*

\begin{tabular}{|c|c|c|c|}
\hline Agent & Action & Effect on NASH pathogenesis & ClinicalTrials.gov identifier \\
\hline GS-9450 & Caspase inhibition & Prevents apoptosis & NCT00740610 [59] \\
\hline GFT-505 & Dual PPAR $\alpha / \delta$ agonist & $\begin{array}{l}\text { Hepatic glucose utilization, lipoprotein metabolism } \\
\text { and anti-inflammatory effects }\end{array}$ & NCT01694849 [60] \\
\hline Obeticholic acid & FXR agonist & $\begin{array}{l}\text { Promotes insulin sensitivity, decreases hepatic } \\
\text { gluconeogenesis and circulating triglycerides }\end{array}$ & NCT01265498 [61] \\
\hline Cenicriviroc & CCR2/CCR5 antagonist & $\begin{array}{l}\text { Interferes with recruitment of monocytes, } \\
\text { macrophages and HSCs upon liver injury }\end{array}$ & NCT02217475 [62] \\
\hline Liraglutide & GLP-1 agonist & Induces insulin secretion, reduces glucagon secretion & NCT01237119 [63] \\
\hline Sitagliptin & DPP-IV inhibitors & Prevents degradation of GLP-1 & NCT01963845 [64] \\
\hline GS-6624 (simtuzumab) & Anti-LOXL-2 antibodies & Inhibits formation and repair of extracellular matrix & $\begin{array}{l}\text { NCT01672879 [65]/ } \\
\text { NCT01672866 [66] }\end{array}$ \\
\hline
\end{tabular}

CCR, C-C chemokine receptor; DPP-IV, dipeptidyl peptidase-4; FXR, farnesoid X receptor; GLP-1, glucagon-like peptide-1; HSC, hepatic stellate cell; LOXL-2, lysyl oxidase-like 2; NASH, nonalcoholic steatohepatitis; PPAR, peroxisome proliferator-activated receptor.

${ }^{*}$ Clinicaltrials.gov accessed on 28 January 2015.

tests, dyslipidaemia and insulin sensitivity in obese, insulin-resistant patients [70,71]. A phase $2 \mathrm{~b}$ RCT is now ongoing based on these encouraging results [60].

\section{Farnesoid $X$ receptor agonists (obeticholic acid)}

Bile acids act as metabolic signalling molecules, aiding dietary lipid absorption, and are involved in cholesterol homeostasis; they are reabsorbed into the enterohepatic circulation and direct hepatic triglyceride and glucose metabolism. They activate nuclear hormone receptor farnesoid $\mathrm{X}$ receptor (FXR) and the G protein-coupled cell surface receptor transmembrane $G$ protein-coupled receptor, which inhibit hepatic de-novo lipogenesis, hepatic gluconeogenesis and glycogenolysis and improve insulin sensitivity. In animal studies, FXR activation has anti-inflammatory actions, partly by inhibiting NF-кB $[72,73]$. In-vivo evidence exists for a protective effect of FXR agonists against liver inflammation and fibrosis in the methionine-cholinedeficient model of NASH [74]. Thus, obeticholic acid, an FXR agonist, was studied in a small pilot trial of 23 diabetic patients with NAFLD. Patients received 6 weeks of the study drug at either $25 \mathrm{mg}$ or $50 \mathrm{mg}$ daily or placebo. Patients on the study drug lost weight with an associated fall in serum $\gamma$-glutamyl transferase and an improvement in the noninvasive Enhanced Liver Fibrosis panel observed more often than in the placebo group [75"].

A 72-week trial of 273 patients with NASH randomized to obeticholic acid or placebo has recently reported evidence of significant reductions in histologically defined endpoints including degree of steatosis, grade of inflammation/ballooning degeneration and stage of fibrosis [76"']. These changes were accompanied by mild weight loss and improved clinical biochemistry parameters, also consistent with reduced liver injury. However, a rise in total cholesterol and a disadvantageous change in high-density lipoprotein/low-density lipoprotein ratio were also observed with obeticholic acid treatment $\left[76^{-"}\right]$. Despite this, the agent remains one of the first in which robust, beneficial changes in liver histology have been identified.

Other promising agents with anti-inflammatory, antifibrotic or insulin-sensitizing properties currently in development or undergoing testing in RCTs in NASH include dual C-C chemokine receptor $2 / 5$ antagonists, glucagon-like peptide- 1 agonists, dipeptidyl peptidase- 4 inhibitors and antilysyl oxidase-like 2 antibodies (simtuzumab).

\section{Hepatocellular carcinoma}

Obesity and diabetes have been well established as risk factors for HCC [77-79]. Recently, HCC has been linked to NAFLD [80], and there is mounting evidence that the same PNPLA3 genetic variant (I148 M, rs738409) that has long been associated with progressive NAFLD also confers an increased risk of NAFLD-HCC [81,82"]. The prevalence of HCC in cirrhotic NAFLD remains undetermined [83], although steatohepatitis was identified as the underlying aetiology in $24 \%$ of patients in a series of HCC surpassing all other causes of chronic liver disease [70] and this trend is set to increase further. In the United Kingdom, a more than 10-fold increase in NAFLD-associated HCC has been observed from 2000 to 2010, with NAFLD-HCC accounting for $34.8 \%$ of all HCC cases [84]. It is increasingly recognized that NAFLD is a cause of noncirrhotic HCC. A recent Japanese cross-sectional study analyzed 87 cases of HCC occurring in patients with 
histologically characterized steatohepatitis; no established cirrhosis was demonstrated in 43 cases [85]. Most worryingly, HCC has been reported in patients even without steatohepatitis [86]. An analysis of a US insurance claims database found NAFLD was the leading condition associated with HCC, with cirrhosis reported in just $46 \%$ of these cases [87].

Adipose tissue expansion and subsequent release of proinflammatory cytokines/adipokines [88,89] and lipotoxicity [90] together promote insulin resistance; hyperinsulinaemia results in increased bioavailability of insulin growth factor-1, which further stimulates cellular proliferation and inhibits apoptosis [91]. Metformin, a biguanide that activates adenosine monophosphate-activated protein kinase and has antiproliferative effects has been shown to inhibit hepatocyte proliferation and induce cell-cycle arrest in hepatoma cell lines [92]. Consequently, targeting insulin resistance with metformin has been investigated in observational and case-control studies of HCC $[93,94]$. Among patients with type 2 diabetes mellitus, metformin was associated with an estimated $62 \%$ reduction in the risk of HCC in a recent meta-analysis (odds ratio, 0.38; 95\% confidence interval, 0.24-0.59) [95]. However, the ability of metformin to protect against NASH-associated carcinogenesis is not firmly established as human data are retrospective and do not mitigate against treatment assignment bias.

There is biological plausibility that statins reduce cancer risk via HCC-specific (Myc inactivation)
$[96,97]$ as well as antiproliferative, proapoptotic, antiangiogenic, immunomodulatory and antiinfective mechanisms [98-100]. A recent meta-analysis examining over 1.4 million patients found results to be heterogeneous [101"]. Data from observational studies indicated that statins lowered the risk of HCC in various patient populations; however, no clear benefit was found when only rigorously conducted RCTs were included in the analysis [101"].

\section{Bariatric surgery}

Surgical weight loss interventions have been investigated in the treatment of NAFLD; the most common procedures tested are laparoscopic adjustable gastric banding and Roux-en-Y gastric bypass. Several uncontrolled studies have reported that bariatric surgery has shown to produce significant weight loss and may be beneficial for the treatment of NAFLD [102,103], but the lack of RCTs precluded this conclusion in a Cochrane review [104]. Nevertheless, a recent study reported that on postbariatric biopsy of 160 patients, steatosis resolved in $75 \%$ and steatohepatitis resolved in 90\%. Fibrosis of any grade resolved in 53\% of patients, with even bridging fibrosis resolved in $29 \%$ of patients [105]. The effects of bariatric surgery on steatosis and ballooning appear durable in a 5-year sequential biopsy study, but fibrosis worsened significantly, although more than $95 \%$ of patients had a fibrosis score F1 or less at 5 years [106]. Clearly, surgical intervention is not a panacea for all patients with NASH, and more

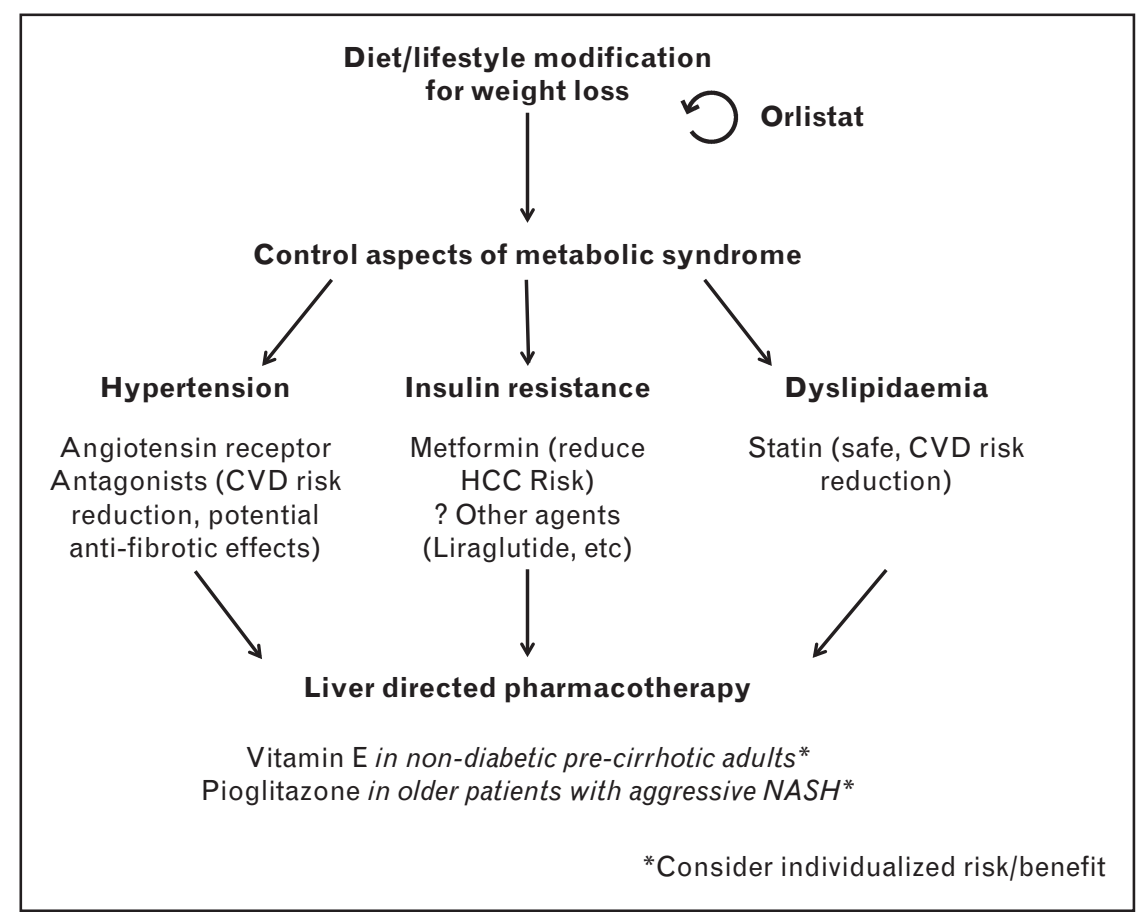

FIGURE 1. Evidence-based schematic for treatment of nonalcoholic steatohepatitis using currently available agents. 
robust data from RCTs are needed before recommendations can be made.

\section{CONCLUSION}

Despite its prevalence and rising incidence, NAFLD is marked by substantial interpatient variability in prognosis and continues to lack the breadth of therapeutic research and development shared by other causes of chronic liver disease. Although major advances have been made in understanding pathogenesis and also identification of genetic modifiers of liver injury extending beyond simple steatosis including PNPLA3 and TM6SF2 $\left[81,107,108^{-"}\right]$, these advances have not yet been fully capitalized upon and so we lack effective pharmacotherapy. Diet and lifestyle modification remain the mainstay of treatment. For patients with NASH and advanced fibrosis, current liver-directed pharmacotherapy with vitamin E and pioglitazone offer some benefits in selected cases. Figure 1 provides a schematic of treatment, once the diagnosis of NASH has been made. However, the beneficial effects of these therapies must be balanced with the potential adverse effects, limiting their widespread use. Coexisting comorbidity must be diagnosed and treated because CVD remains primary cause of death in these patients. The new agents currently in trial provide the first hope of effective, targeted pharmacotherapy in this field.

\section{Acknowledgements}

None.

\section{Financial support and sponsorship}

Q.M.A. is the recipient of a Clinical Senior Lectureship Award from the Higher Education Funding Council for England (HEFCE). T.H. is the recipient of a Clinical Research Fellowship Award from the Medical Research Council (MRC), UK.

\section{Conflicts of interest}

Q.M.A. has received research grant funding from GlaxoSmithKline, honoraria for lecturing from Abbott Laboratories and has performed consultancy for GENFIT, Synageva, NewGene and Acuitas Medical.

\section{REFERENCES AND RECOMMENDED \\ READING}

Papers of particular interest, published within the annual period of review, have been highlighted as:

- of special interest

- of outstanding interest

1. Anstee QM, Targher G, Day CP. Progression of NAFLD to diabetes mellitus, cardiovascular disease or cirrhosis. Nat Rev Gastroenterol Hepatol 2013; 10:330-344

2. Ekstedt M, Franzen LE, Mathiesen UL, et al. Long-term follow-up of patients with NAFLD and elevated liver enzymes. Hepatology 2006; 44:865-873.
3. Argo $\mathrm{CK}$, Caldwell SH. Epidemiology and natural history of nonalcoholic steatohepatitis. Clin Liver Dis 2009; 13:511-531.

4. Ratziu V, Bellentani $\mathrm{S}$, Cortez-Pinto $\mathrm{H}$, et al. A position statement on NAFLD/ NASH based on the EASL 2009 special conference. J Hepatol 2010; 53:372-384

5. McPherson S, Hardy T, Henderson E, et al. Evidence of NAFLD progression

In from steatosis to fibrosing-steatohepatitis using paired biopsies: implications for prognosis and clinical management. J Hepatol 2014. doi: http:// dx.doi.org/10.1016/j.jhep.2014.11.034.

Largest paired-biopsy cohort to date (108 patients) demonstrating progression to fibrosing steatohepatitis from steatosis.

6. Harrison SA, Fecht W, Brunt EM, et al. Orlistat for overweight subjects with nonalcoholic steatohepatitis: a randomized, prospective trial. Hepatology 2009; 49:80-86.

7. Zelber-Sagi S, Kessler A, Brazowsky E, et al. A double-blind randomized placebo-controlled trial of orlistat for the treatment of nonalcoholic fatty liver disease. Clin Gastroenterol Hepatol 2006; 4:639-644.

8. Promrat $\mathrm{K}$, Kleiner DE, Niemeier HM, et al. Randomized controlled trial testing the effects of weight loss on nonalcoholic steatohepatitis. Hepatology 2010; 51:121-129.

9. Thoma C, Day CP, Trenell Ml. Lifestyle interventions for the treatment of nonalcoholic fatty liver disease in adults: a systematic review. J Hepatol 2012; 56:255-266

10. Franz MJ, VanWormer JJ, Crain AL, et al. Weight-loss outcomes: a systematic review and meta-analysis of weight-loss clinical trials with a minimum 1-year follow-up. J Am Diet Assoc 2007; 107:1755-1767.

11. Hallsworth K, Fattakhova G, Hollingsworth KG, et al. Resistance exercise reduces liver fat and its mediators in nonalcoholic fatty liver disease independent of weight loss. Gut 2011; 60:1278-1283.

12. Sanyal AJ, Chalasani N, Kowdley KV, et al. Pioglitazone, vitamin E, or placebo for nonalcoholic steatohepatitis. N Engl J Med 2010; 362:16751685.

13. Singh S, Loke YK, Furberg CD. Long-term risk of cardiovascular events with rosiglitazone: a meta-analysis. J Am Med Assoc 2007; 298:1189-1195.

14. Neumann $A$, Weill $A$, Ricordeau $P$, et al. Pioglitazone and risk of bladder cancer among diabetic patients in France: a population-based cohort study. Diabetologia 2012; 55:1953-1962.

15. Miller ER 3rd, Pastor-Barriuso R, Dalal D, et al. Meta-analysis: high-dosage vitamin $\mathrm{E}$ supplementation may increase all-cause mortality. Ann Intern Med $2005 ; 142: 37-46$.

16. Lavine JE, Schwimmer JB, Van Natta ML, et al. Effect of vitamin $E$ or metformin for treatment of nonalcoholic fatty liver disease in children and adolescents: the TONIC randomized controlled trial. J Am Med Assoc 2011; 305:1659-1668.

17. Haukeland JW, Konopski Z, Eggesbo HB, et al. Metformin in patients with nonalcoholic fatty liver disease: a randomized, controlled trial. Scand J Gastroenterol 2009; 44:853-860.

18. Foster T, Budoff MJ, Saab S, et al. Atorvastatin and antioxidants for the treatment of nonalcoholic fatty liver disease: the St Francis Heart Study randomized clinical trial. Am J Gastroenterol 2011; 106:71-77.

19. Athyros VG, Tziomalos K, Gossios TD, et al. Safety and efficacy of long-term statin treatment for cardiovascular events in patients with coronary heart disease and abnormal liver tests in the Greek Atorvastatin and Coronary Heart Disease Evaluation (GREACE) Study: a posthoc analysis. Lancet 2010; 376:1916-1922.

20. Nelson A, Torres DM, Morgan AE, et al. A pilot study using simvastatin in the treatment of nonalcoholic steatohepatitis: a randomized placebo-controlled trial. J Clin Gastroenterol 2009; 43:990-994.

21. Orlando $R$, Azzalini $L$, Orando $S$, et al. Bile acids for nonalcoholic fatty liver disease and/or steatohepatitis. Cochrane Database Syst Rev 2007; (1):CD005160.

22. Sanyal AJ, Abdelmalek MF, Suzuki A, et al. No significant effects of ethyl-

- eicosapentanoic acid on histologic features of nonalcoholic steatohepatitis in a phase 2 trial. Gastroenterology 2014; 147:377-384.

Two hundred forty three patients assigned to placebo, low or high-dose ethyleicosapentaenoic acid-E with no significant effects on histology or biochemistry.

23. Argo CK, Patrie JT, Lackner C, et al. Effects of $n-3$ fish oil on metabolic and histological parameters in NASH: a double-blind, randomized, placebocontrolled trial. J Hepatol 2015; 62:190-197.

24. Yokohama S, Yoneda $M$, Haneda $M$, et al. Therapeutic efficacy of an angiotensin II receptor antagonist in patients with nonalcoholic steatohepatitis. Hepatology 2004; 40:1222-1225.

25. Zein CO, Yerian LM, Gogate $P$, et al. Pentoxifylline improves nonalcoholic steatohepatitis: a randomized placebo-controlled trial. Hepatology 2011; 54:1610-1619

26. Frohnert BI, Hui TY, Bernlohr DA. Identification of a functional peroxisome proliferator-responsive element in the murine fatty acid transport protein gene. J Biol Chem 1999; 274:3970-3977.

27. Tontonoz P, Hu E, Graves RA, et al. mPPAR gamma 2: tissue-specific regulator of an adipocyte enhancer. Genes Dev 1994; 8:1224-1234.

28. Sears IB, MacGinnitie MA, Kovacs LG, et al. Differentiation-dependent expression of the brown adipocyte uncoupling protein gene: regulation by peroxisome proliferator-activated receptor gamma. Mol Cell Biol 1996; $16: 3410-3419$ 
29. Kim JB, Spiegelman BM. ADD1/SREBP1 promotes adipocyte differentiation and gene expression linked to fatty acid metabolism. Genes Dev 1996; 10:1096-1107.

30. Galli A, Crabb DW, Ceni E, et al. Antidiabetic thiazolidinediones inhibit collagen synthesis and hepatic stellate cell activation in vivo and in vitro. Gastroenterology 2002; 122:1924-1940.

31. Marra F, Efsen E, Romanelli RG, et al. Ligands of peroxisome proliferatoractivated receptor gamma modulate profibrogenic and proinflammatory actions in hepatic stellate cells. Gastroenterology 2000; 119:466-478.

32. Miyahara $T$, Schrum L, Rippe R, et al. Peroxisome proliferator-activated receptors and hepatic stellate cell activation. J Biol Chem 2000; 275:3571535722.

33. Odegaard Jl, Ricardo-Gonzalez RR, Goforth $\mathrm{MH}$, et al. Macrophage-specific PPARgamma controls alternative activation and improves insulin resistance. Nature 2007; 447:1116-1120.

34. $\mathrm{Yu}$ JG, Javorschi $\mathrm{S}$, Hevener $\mathrm{AL}$, et al. The effect of thiazolidinediones on plasma adiponectin levels in normal, obese, and type 2 diabetic subjects. Diabetes 2002; 51:2968-2974

35. Tonelli J, Li W, Kishore $\mathrm{P}$, et al. Mechanisms of early insulin-sensitizing effects of thiazolidinediones in type 2 diabetes. Diabetes 2004; 53:1621-1629.

36. Belfort R, Harrison SA, Brown $\mathrm{K}$, et al. A placebo-controlled trial of pioglitazone in subjects with nonalcoholic steatohepatitis. N Engl J Med 2006; 355:2297-2307

37. Aithal GP, Thomas JA, Kaye PV, et al. Randomized, placebo-controlled trial of pioglitazone in nondiabetic subjects with nonalcoholic steatohepatitis. Gastroenterology 2008; 135:1176-1184.

38. Ratziu V, Giral $P$, Jacqueminet $S$, et al. Rosiglitazone for nonalcoholic steatohepatitis: one-year results of the randomized placebo-controlled Fatty Liver Improvement with Rosiglitazone Therapy (FLIRT) Trial. Gastroenterology $2008 ; 135: 100-110$.

39. Lutchman G, Modi A, Kleiner DE, et al. The effects of discontinuing pioglitazone in patients with nonalcoholic steatohepatitis. Hepatology 2007; 46:424-429.

40. Mahady SE, Webster AC, Walker S, et al. The role of thiazolidinediones in nonalcoholic steatohepatitis: a systematic review and meta analysis. J Hepatol 2011; 55:1383-1390.

41. Murphy CE, Rodgers PT. Effects of thiazolidinediones on bone loss and fracture. Ann Pharmacother 2007; 41:2014-2018.

42. Chalasani N, Younossi Z, Lavine JE, et al. The diagnosis and management of nonalcoholic fatty liver disease: practice Guideline by the American Association for the Study of Liver Diseases, American College of Gastroenterology, and the American Gastroenterological Association. Hepatology 2012; 55:2005-2023

43. Parola $M$, Muraca $R$, Dianzani I, et al. Vitamin $E$ dietary supplementation inhibits transforming growth factor beta 1 gene expression in the rat liver. FEBS Lett 1992; 308:267-270.

44. Houglum K, Venkataramani A, Lyche $K$, et al. A pilot study of the effects of d-alpha-tocopherol on hepatic stellate cell activation in chronic hepatitis C. Gastroenterology 1997; 113:1069-1073.

45. Morante M, Sandoval J, Gomez-Cabrera MC, et al. Vitamin E deficiency induces liver nuclear factor-kappaB DNA-binding activity and changes in related genes. Free Radic Res 2005; 39:1127-1138.

46. Soden JS, Devereaux MW, Haas JE, et al. Subcutaneous vitamin E ameliorates liver injury in an in vivo model of steatocholestasis. Hepatology 2007; 46:485-495.

47. Sokol RJ, McKim JM Jr, Goff MC, et al. Vitamin E reduces oxidant injury to mitochondria and the hepatotoxicity of taurochenodeoxycholic acid in the rat. Gastroenterology 1998; 114:164-174.

48. Sanyal AJ, Mofrad PS, Contos MJ, et al. A pilot study of vitamin E versus vitamin $E$ and pioglitazone for the treatment of nonalcoholic steatohepatitis. Clin Gastroenterol Hepatol 2004; 2:1107-1115.

49. Klein EA, Thompson IM Jr, Tangen CM, et al. Vitamin E and the risk of prostate cancer: the Selenium and Vitamin E Cancer Prevention Trial (SELECT). J Am Med Assoc 2011; 306:1549-1556.

50. Schurks M, Glynn RJ, Rist PM, et al. Effects of vitamin E on stroke subtypes: meta-analysis of randomised controlled trials. BMJ 2010; 341:c5702.

51. Lin HZ, Yang SQ, Chuckaree C, et al. Metformin reverses fatty liver disease in obese, leptin-deficient mice. Nat Med 2000; 6:998-1003.

52. Torres DM, Jones FJ, Shaw JC, et al. Rosiglitazone versus rosiglitazone and metformin versus rosiglitazone and losartan in the treatment of nonalcoholic steatohepatitis in humans: a 12-month randomized, prospective, open-label trial. Hepatology $2011 ; 54: 1631-1639$.

53. Loomba R, Lutchman $\mathrm{G}$, Kleiner $\mathrm{DE}$, et al. Clinical trial: pilot study of metformin for the treatment of nonalcoholic steatohepatitis. Aliment Pharmacol Ther 2009; 29:172-182.

54. Chalasani N, Aljadhey $\mathrm{H}$, Kesterson J, et al. Patients with elevated liver enzymes are not at higher risk for statin hepatotoxicity. Gastroenterology 2004; 126:1287-1292.

55. Lindor KD, Kowdley KV, Heathcote EJ, et al. Ursodeoxycholic acid for treatment of nonalcoholic steatohepatitis: results of a randomized trial. Hepatology 2004; 39:770-778.

56. Oakley F, Teoh V, Ching ASG, et al. Angiotensin II activates I kappaB kinase phosphorylation of RelA at Ser 536 to promote myofibroblast survival and liver fibrosis. Gastroenterology 2009; 136:2334-2344.
57. Koppe SW, Sahai $A$, Malladi $P$, et al. Pentoxifylline attenuates steatohepatitis induced by the methionine choline deficient diet. J Hepatol 2004; 41:592598.

58. Preaux AM, Mallat $A$, Rosenbaum J, et al. Pentoxifylline inhibits growth and collagen synthesis of cultured human hepatic myofibroblast-like cells. $\mathrm{He}$ patology $1997 ; 26: 315-322$.

59. US National Library of Medicine. Safety, tolerability, pharmacokinetics and activity of GS-9450 in adults with non-alcoholic steatohepatitis (NASH). 2014. https://clinicaltrials.gov/ct2/show/NCT00740610?term=GS-9450\& rank=2. [Accessed 28 January 2015]

60. US National Library of Medicine. Phase Ilb study to evaluate the efficacy and safety of GFT505 versus placebo in patients with non-alcoholic steatohepatitis (NASH). 2015. https://clinicaltrials.gov/ct2/show/NCT0169 4849?term=GFT-505\&rank=4. [Accessed 28 January 2015]

61. US National Library of Medicine. The farnesoid $X$ receptor (FXR) ligand obeticholic acid in NASH treatment trial (FLINT). 2014. https://clinicaltrials. gov/ct2/show/NCT01265498?term=obeticholic+acid\&rank=1. [Accessed 28 January 2015]

62. US National Library of Medicine. Efficacy and safety study of cenicriviroc for the treatment of NASH in adult subjects with liver fibrosis (CENTAUR). 2014. https://clinicaltrials.gov/ct2/show/NCT02217475?term=cenicriviroc\&rank $=5$. [Accessed 28 January 2015]

63. US National Library of Medicine. Liraglutide efficacy and action in nonalcoholic steatohepatitis (LEAN). 2013. https://clinicaltrials.gov/ct2/show/ NCT01237119?term=liraglutide+NAFLD\&rank=3. [Accessed 28 January 2015]

64. US National Library of Medicine. Sitagliptin versus placebo in the treatment of nonalcoholic fatty liver disease. 2013. https://clinicaltrials.gov/ct2/show/ NCT01963845?term=sitagliptin+NASH\&rank=2. [Accessed 28 January 2015]

65. US National Library of Medicine. Simtuzumab (GS-6624) in the treatment of cirrhosis due to NASH. 2014. https://clinicaltrials.gov/ct2/show/NCT0167 2879?term=simtuzumab+NASH\&rank=1. [Accessed 28 January 2015]

66. US National Library of Medicine. Safety and efficacy of simtuzumab (GS6624 ) in adults with advanced liver fibrosis but not cirrhosis secondary to non-alcoholic steatohepatitis (NASH). 2014. https://clinicaltrials.gov/ct2/ show/NCT01672866?term=simtuzumab+NASH\&rank=2. [Accessed 28 January 2015]

67. Anstee $\mathrm{QM}$, Concas $\mathrm{D}$, Kudo $\mathrm{H}$, et al. Impact of pan-caspase inhibition in animal models of established steatosis and nonalcoholic steatohepatitis. J Hepatol 2010; 53:542-550.

68. Ratziu V, Sheikh MY, Sanyal AJ, et al. A phase 2, randomized, double-blind, placebo-controlled study of GS-9450 in subjects with nonalcoholic steatohepatitis. Hepatology 2012; 55:419-428.

69. Staels B, Rubenstrunk A, Noel B, et al. Hepatoprotective effects of the dual

- peroxisome proliferator-activated receptor alpha/delta agonist, GFT505, in rodent models of nonalcoholic fatty liver disease/nonalcoholic steatohepatitis. Hepatology 2013; 58:1941-1952.

GFT-505 improves liver enzymes (ALT, $\gamma$-glutamyl transferase, alkaline phosphatase) in insulin-resistant patients.

70. Cariou B, Zair Y, Staels B, et al. Effects of the new dual PPAR alpha/delta agonist GFT505 on lipid and glucose homeostasis in abdominally obese patients with combined dyslipidemia or impaired glucose metabolism. Diabetes Care 2011; 34:2008-2014.

71. Cariou $B$, Hanf $R$, Lambert-Porcheron $S$, et al. Dual peroxisome proliferatoractivated receptor alpha/delta agonist GFT505 improves hepatic and peripheral insulin sensitivity in abdominally obese subjects. Diabetes Care 2013; 36:2923-2930.

72. Wagner M, Zollner G, Trauner M. Nuclear bile acid receptor farnesoid X receptor meets nuclear factor-kappaB: new insights into hepatic inflammation. Hepatology 2008; 48:1383-1386.

73. Wang YD, Chen WD, Wang $M$, et al. Farnesoid $X$ receptor antagonizes nuclear factor kappaB in hepatic inflammatory response. Hepatology 2008; 48:1632-1643.

74. Zhang $S$, Wang J, Liu $Q$, et al. Farnesoid $X$ receptor agonist WAY-362450 attenuates liver inflammation and fibrosis in murine model of nonalcoholic steatohepatitis. J Hepatol 2009; 51:380-388.

75. Mudaliar S, Henry RR, Sanyal AJ, et al. Efficacy and safety of the farnesoid X

- receptor agonist obeticholic acid in patients with type 2 diabetes and nonalcoholic fatty liver disease. Gastroenterology 2013; 145:574582.

Proof-of-concept study testing FXR agonist in patients with type 2 diabetes mellitus and NAFLD.

76. Neuschwander-Tetri BA, Loomba R, Sanyal AJ, et al. Farnesoid X nuclear

- receptor ligand obeticholic acid for noncirrhotic, nonalcoholic steatohepatitis (FLINT): a multicentre, randomised, placebo-controlled trial. Lancet 2014. DOI: http://dx.doi.org/10.1016/S0140-6736(14)61933-4.

Obeticholic acid is one of the first agents where robust, beneficial changes in liver histology have been identified in patients with NASH.

77. Bianchini F, Kaaks R, Vainio H. Overweight, obesity, and cancer risk. Lancet Oncol 2002; 3:565-574

78. Calle EE, Rodriguez $\mathrm{C}$, Walker-Thurmond $\mathrm{K}$, et al. Overweight, obesity, and mortality from cancer in a prospectively studied cohort of U.S. adults. N Engl J Med 2003; 348:1625-1638. 
79. El-Serag HB, Hampel H, Javadi F. The association between diabetes and hepatocellular carcinoma: a systematic review of epidemiologic evidence. Clin Gastroenterol Hepatol 2006; 4:369-380.

80. Abdelmalek MF, Diehl AM. Nonalcoholic fatty liver disease as a complication of insulin resistance. Med Clin North Am 2007; 91:1125-1149.

81. Valenti L, Al-Serri A, Daly AK, et al. Homozygosity for the patatin-like phospholipase-3/adiponutrin I148 M polymorphism influences liver fibrosis in patients with nonalcoholic fatty liver disease. Hepatology 2010; 51:12091217.

82. Liu YL, Patman GL, Leathart JB, et al. Carriage of the PNPLA3 rs738409 C

- $>\mathrm{G}$ polymorphism confers an increased risk of nonalcoholic fatty liver disease associated hepatocellular carcinoma. J Hepatol 2014; 61:7581.

The polymorphism conferring progressive NAFLD also increases the risk of NAFLD-HCC.

83. Baffy G, Brunt EM, Caldwell SH. Hepatocellular carcinoma in nonalcoholic fatty liver disease: an emerging menace. J Hepatol 2012; 56:13841391.

84. Dyson J, Jaques B, Chattopadyhay D, et al. Hepatocellular cancer: the impact of obesity, type 2 diabetes and a multidisciplinary team. J Hepatol 2014; 60:110-117.

85. Yasui $\mathrm{K}$, Hashimoto $\mathrm{E}$, Komorizono $\mathrm{Y}$, et al. Characteristics of patients with nonalcoholic steatohepatitis who develop hepatocellular carcinoma. Clin Gastroenterol Hepatol 2011; 9:428-433.

86. Guzman G, Brunt EM, Petrovic LM, et al. Does nonalcoholic fatty liver disease predispose patients to hepatocellular carcinoma in the absence of cirrhosis? Arch Pathol Lab Med 2008; 132:1761-1766.

87. Sanyal A, Poklepovic A, Moyneur E, et al. Population-based risk factors and resource utilization for HCC: US perspective. Curr Med Res Opin 2010; 26:2183-2191.

88. Hotamisligil GS. Inflammation and metabolic disorders. Nature 2006; 444:860-867.

89. Marra F, Bertolani C. Adipokines in liver diseases. Hepatology 2009; 50:957-969.

90. Unger RH, Clark GO, Scherer PE, et al. Lipid homeostasis, lipotoxicity and the metabolic syndrome. Biochim Biophys Acta 2010; 1801:209214.

91. Ohlsson C, Mohan S, Sjogren $\mathrm{K}$, et al. The role of liver-derived insulin-like growth factor-I. Endocr Rev 2009; 30:494-535.

92. Chen HP, Shieh JJ, Chang CC, et al. Metformin decreases hepatocellular carcinoma risk in a dose-dependent manner: population-based and in vitro studies. Gut 2013; 62:606-615.

93. Nkontchou G, Cosson $\mathrm{E}$, Aout $\mathrm{M}$, et al. Impact of metformin on the prognosis of cirrhosis induced by viral hepatitis $\mathrm{C}$ in diabetic patients. J Clin Endocrinol Metab 2011; 96:2601-2608.
94. Donadon V, Balbi M, Mas MD, et al. Metformin and reduced risk of hepatocellular carcinoma in diabetic patients with chronic liver disease. Liver Int 2010; 30:750-758

95. Zhang ZJ, Zheng ZJ, Shi R, et al. Metformin for liver cancer prevention in patients with type 2 diabetes: a systematic review and meta-analysis. J Clin Endocrinol Metab 2012; 97:2347-2353.

96. Shachaf CM, Kopelman AM, Arvanitis C, et al. MYC inactivation uncovers pluripotent differentiation and tumour dormancy in hepatocellular cancer. Nature 2004; 431:1112-1117.

97. Cao Z, Fan-Minogue $\mathrm{H}$, Bellovin DI, et al. MYC phosphorylation, activation, and tumorigenic potential in hepatocellular carcinoma are regulated by HMGCoA reductase. Cancer Res 2011; 71:2286-2297.

98. Demierre MF, Higgins PD, Gruber SB, et al. Statins and cancer prevention. Nat Rev Cancer 2005; 5:930-942.

99. Wu J, Wong WW, Khosravi F, et al. Blocking the Raf/MEK/ERK pathway sensitizes acute myelogenous leukemia cells to lovastatin-induced apoptosis. Cancer Res 2004; 64:6461-6468.

100. Marcelli M, Cunningham GR, Haidacher SJ, et al. Caspase-7 is activated during lovastatin-induced apoptosis of the prostate cancer cell line LNCaP. Cancer Res 1998; 58:76-83.

101. Singh S, Singh PP, Singh AG, et al. Statins are associated with a reduced

- risk of hepatocellular cancer: a systematic review and meta-analysis. Gastroenterology 2013; 144:323-332.

Meta-analysis of seven observational studies and three studies reporting pooled

data from 26 RCTs.

102. Liu X, Lazenby AJ, Clements $\mathrm{RH}$, et al. Resolution of nonalcoholic steatohepatits after gastric bypass surgery. Obes Surg 2007; 17:486-492.

103. Barker KB, Palekar NA, Bowers SP, et al. Nonalcoholic steatohepatitis: effect of Roux-en-Y gastric bypass surgery. Am J Gastroenterol 2006; 101:368-373.

104. Chavez-Tapia NC, Tellez-Avila FI, Barrientos-Gutierrez T, et al. Bariatric surgery for nonalcoholic steatohepatitis in obese patients. Cochrane Database Syst Rev 2010; (1):CD007340.

105. Taitano AA, Markow M, Finan JE, et al. Bariatric surgery improves histological features of nonalcoholic fatty liver disease and liver fibrosis. J Gastrointest Surg 2014. doi: http://dx.doi.org/10.1007/s11605-014-2678-y.

106. Mathurin $P$, Hollebecque $A$, Arnalsteen $L$, et al. Prospective study of the longterm effects of bariatric surgery on liver injury in patients without advanced disease. Gastroenterology 2009; 137:532-540.

107. Anstee QM, Day CP. The genetics of NAFLD. Nat Rev Gastroenterol Hepatol 2013; 10:645-655.

108. Liu YL, Reeves HL, Burt AD, et al. TM6SF2 rs58542926 influences hepatic

- fibrosis progression in patients with nonalcoholic fatty liver disease. Nat Commun 2014; 5:4309.

The first report demonstrating an association between TM6SF2 variant and fibrosis in NAFLD. 